\title{
Outsourcing and Structural Change. An application to a set of OECD countries*
}

\author{
Sandro Montresor ${ }^{\dagger} \quad$ Giuseppe Vittucci Marzetti ${ }^{\ddagger}$
}

\begin{abstract}
The paper aims at bridging outsourcing and structural change analysis in order to obtain more accurate insights on the actual extent of the former and draw more reliable policy implications to deal with its effects. Such a bridge is set at work by applying a "battery" of outsourcing measurements to some OECD countries over the '80s and the middle '90s. On the one hand, standard results (e.g. the idiosyncratic outsourcing patterns of the UK) are confirmed on a more systematic and comparable basis. On the other hand, original results (e.g. the low integration of business services into manufacturing of the former socialist economies) are obtained by exploiting new available data.
\end{abstract}

Keywords: Outsourcing; Input-output; Vertical integration; Tertiarisation; Manufacturing.

JEL Classification: D230, D570, L160, L220, L240, L600, O140.

\footnotetext{
${ }^{*}$ The two authors contributed equally to Sections 1 and 4. Section 2 is the work mainly of Sandro Montresor. Section 3 is the work mainly of Giuseppe Vittucci Marzetti. The authors are indebted to Malcolm Sawyer and to an anonymous referee for their comments on an earlier version of the article. The authors gratefully acknowledge financial support by the Autonomous Province of Trento (Italy), as the sponsor of, respectively, the OPENLOC research project under the call for proposals "Major Projects 2006" (both of them), and a post-doc 2006 scholarship (Giuseppe Vittucci Marzetti). The usual disclaimers apply.

${ }^{\dagger}$ Dpt. of Economics, University of Bologna, Italy, E-mail: sandro.montresor@.unibo.it

${ }^{\ddagger}$ Dpt. of Economics, University of Trento, Italy, E-mail: giuseppe.vittucci@unitn.it
} 
"Outsourcing and offshoring. . involve the vertical breakup of previously integrated sectors, on the basis of superior capabilities, leveraged across sectors in newly emerging "industries" that cut across traditional classifications. Such transformations also suggest that we may need to reconsider the boundaries of existing industries, which are actively redrawn as a result of the process of vertical disintegration and reintegration...We need a new empiricism, which defines industries in a more dynamic way, transcending the traditional SIC definitions, and focuses on the comparative analysis of value chain instead."

(Jacobides \& Winter, 2005, p.410)

\section{Introduction}

Outsourcing is emerging as an extremely pervasive economic phenomenon (e.g. Domberger, 1998; Spencer, 2005). Important implications have been identified and debated about it in terms of: firms' costs and profitability (e.g. Gorg \& Hanley, 2004); contractual relationships, technology and growth patterns (e.g. Acemoglu et al., 2002; Naghavi \& Ottaviano, 2005); international fragmentation of production processes and cross-countries trade patterns (e.g. Baldone et al., 2002; Kohler, 2004; Jones \& Kierzkowski, 2001); upgrading of global value-chains and development strategies (e.g. Gereffi, 2003; Humphrey \& Schmitz, 2002).

Less attention has been paid to its implications in terms of structural change, that is in reconfiguring the sectoral structure of the economic systems. In fact, since the seminal work by Momigliano \& Siniscalco (1982), along with other contributions in the '80s (e.g. Stanback, 1979; Ginzberg \& Vojta, 1981; McFetridge \& Smith, 1988), few efforts have been devoted to this issue. Mainly for decomposing aggregated growth patterns, rather than investigating disaggregated patterns of change (e.g. Dietrich, 1999; McCarthy \& Anagnostou, 2004).

This could be due to at least three reasons. First of all, at a theoretical 
level, outsourcing has been traditionally conceived as a switching from "make" to "buy", from the "firm" to the "market", with no other structural change implications but the emergence of market prices in place of internal prices. Second, at a methodological level, Input-Output (IO) tables, the main tool for structural change analysis, have been usually considered unsuitable for investigating firm-specific processes, as they rely on establishment-specific data. Third, at an empirical level, disaggregated sectoral and IO data to measure the structural change implications of outsourcing have been missing for long time.

As we have argued more extensively elsewhere (Montresor \& Vittucci Marzetti, 2006, 2007), these reasons are now less binding and thus allow further research on the topic. Hence, after having recapitulated the main issues in Section 2, in Section 3 we apply some "special" outsourcing measurements at sectoral and sub-system level to a set of OECD countries . ${ }^{1}$ In so doing, the paper aims at investigating to what extent these indicators can show traces of outsourcing records in the structural analysis of the investigated economies and how reliable these traces are. The paper concludes with some

final remarks and the policy implications of our findings (Section 4).

\section{Outsourcing and structural change: research issues}

In the analysis of the structural change implications of outsourcing, the researcher needs to deal with at least three kinds of issues: theoretical, methodological and empirical. Let us briefly consider each of them in turn (for a more extensive analysis see Montresor \& Vittucci Marzetti, 2007).

\subsection{The theoretical issue}

From a theoretical point of view, outsourcing is usually conceived as a process symmetric to vertical integration, since it reduces the "vertical scope" of the firm (for a critical view of this perspective see, among the others, Becker \& Zirpoli, 2009). 
However, such a theoretical account can be contrasted by looking at the firm as an "open system" or an "extended enterprise" (e.g. McCarthy \& Anagnostou, 2004), by arguing that outsourcing makes its boundaries more "permeable" to other organizations and market mechanisms (Jacobides \& Billinger, 2005).

Sticking to one or the other interpretation has different structural change implications. According to the former, the fact that a certain manufacturing firm outsources one of its production activities to an external supplier just diminishes its economic contribution to manufacturing and, in case of business service outsourcing (e.g. of janitorial services), that of manufacturing with respect to services in the economic system: service outsourcing entails nothing but a "tertiarisation" effect. On the contrary, according to the latter, the same outsourcing operations entail a restructuring effect of manufacturing, making it so to say more "transversal". Following this last interpretation, outsourcing is actually a particular kind of structural change, amounting to an extension of manufacturing sectors into non-manufacturing ones (e.g. Dietrich, 1999; McCarthy \& Anagnostou, 2004). Accordingly, the theoretical division between the analysis of outsourcing and that of structural change can be misleading.

\subsection{The methodological issue}

In order to analyse the structural change implications of outsourcing, researchers need data on intersectoral flows. Since IO tables are built up by referring to deliveries of goods and services occurring between different establishments, rather than firms (or enterprises), and since many firms are in fact multi-plant, this might constitute a serious obstacle (e.g. Woodrow Eckard, 1979; Postner, 1990).

However, the insensitivity of IO tables to outsourcing is seldom total and rather depends on the specific circumstances. At most, the sensitivity is quite high when, for instance, a certain establishment substitutes services and/or intermediate inputs provided by an establishment of a different firm, for those previously produced within the establishment itself. Or whenever an establishment contracts-out ancillary activities, which were not counted 
as products in national accounts before outsourcing.

If one deals with service outsourcing, as we mainly do in the present paper, these two cases are probably the most frequent ones. On the one hand, being neither storable nor transportable, services are embedded in establishments rather than in firms. On the other hand, as also explicitly recognized in the SNA93 (United Nations, 2006, par.6.87), even when they entail deliveries between different establishments of a certain firm, it is not always possible to identify and record them separately. Accordingly, also the methodological obstacles to bridge the analysis of outsourcing with that of structural change are not so prohibitive. Moreover, the relative analysis will be the more accurate, the less diversified firms are in their constituting establishments. $^{2}$

\subsection{The empirical issue}

From an empirical point of view, the most straightforward way to capture service outsourcing for structural change analysis is, of course, referring to sectoral measurements (in the following, we will refer to an economic system of $n$ sectors, which is therefore the order of the relative intersectoral matrices). For instance, a first indicator can be obtained by analyzing the changes occurred over time in the transactions (at constant prices) of intermediate business services $\left(S E R V_{i}\right)$ made by the manufacturing firms of sector $i$ per unit of production $\left(Q_{i}\right)$, i.e. in the ratio $S E R V_{i} / Q_{i}$.

A second related indicator is given by those changes occurred in the ratio between the transactions of intermediate business services $\left(S E R V_{i}\right)$ and the value of wages and salaries of the same sector $\left(L A B R_{i}\right)$, i.e. in the ratio $S E R V_{i} / L A B R_{i}$ (McFetridge \& Smith, 1988).

Although with an important signaling power, however, both the indicators require to assume some problematic hypotheses, and should therefore be used with caveats (on this issue, see Montresor \& Vittucci Marzetti, 2007).

Further signals emerge by considering that outsourcing can make standard IO coefficients (Miller \& Blair, 1985) - i.e. the elements of the matrix $\mathbf{A}=\mathbf{Q} \hat{\mathbf{q}}^{-1}$ - change by affecting intersectoral intermediate consumptions (the $\mathbf{Q}$ matrix), total sectoral production (the diagonalised vector $\hat{\mathbf{q}}$ ) and 
sectoral value added. More precisely, ceteris paribus, intrasectoral outsourcing in sector $i$-i.e. involving units of production belonging to the same sector $i-$ increases the intermediate consumption and the gross output of the relevant sector, while leaving its value added hardly affected: accordingly, it determines a change in the relevant IO autocoefficient, $a_{i i}$. The same effect, instead, does not occur in the case of intersectoral outsourcing by sector $i$-i.e. involving production units belonging to two different sectors - because the gross output of the "outsourcer" sector $i$ remains relatively stable, while its value added diminishes: in this case, thus, $a_{i i}$ is not expected to change (for a formal proof of this result, see Montresor \& Vittucci Marzetti, 2007).

Although important in suggesting all these implications, the sectoral level of analysis is however unable to catch the effects outsourcing exerts on the whole set of relationships of an economic system. In trying to capture both vertical and horizontal linkages, and both direct and indirect effects, one should thus rather refer to the concepts of subsystems or vertically integrated sectors. ${ }^{3}$ In particular, drawing on the contribution by Momigliano \& Siniscalco (1982), one can refer to a matrix $\mathbf{C}$ formally defined as:

$$
\mathbf{C}=\hat{\mathbf{l B}}\left(\mathbf{l}^{\prime} \hat{\mathbf{B}}\right)^{-1}
$$

where $\mathbf{l}^{\prime}$ is the row vector of labour inputs, the hat symbol is used to denote diagonalisation and $\mathbf{B}$ is defined as:

$$
\mathbf{B}=\hat{\mathbf{q}}^{-1}(\mathbf{I}-\mathbf{A})^{-1} \hat{\mathbf{y}}
$$

In Eq.(2), $\hat{\mathbf{q}}$ is the diagonalised vector of gross production, $\mathbf{A}$ is the matrix of IO coefficients calculated on the basis of domestic flows and $\hat{\mathbf{y}}$ is the diagonalised vector of total final demand. Each cell $c_{i j}$ of $\mathbf{C}$ (on whose properties see Montresor \& Vittucci Marzetti, 2007) measures the share accounted by sector $i$ in the total labour required by subsystem $j$ to produce the output needed to satisfy the final demand for it.

Starting from this matrix, two useful indicators can be obtained. The first one is given by each element of the main $\mathbf{C}$ diagonal $\left(c_{i i}\right)$. Ranging from 0 to 1 , it can be taken as a proxy of the vertical integration degree of sector $i$ : the closer $c_{i i}$ is to 0 , the more sector $i$ will be vertically disintegrated, the more outsourcing processes can be retained relevant for it. 
The second indicator is given by the sum, for each column $i$, of the rows of $\mathbf{C}$, say from $m$ to $n$, which refer to business sector services $\left(\sum_{k=m}^{n} c_{k i}\right)$. This is a proxy of the service integration in the subsystem $i$ : the higher this sum, the more market services are integrated into the relevant manufacturing subsystem, the more service outsourcing is presumable in place.

These two indicators refer to what can be called "system" integration, determined by both technological and organizational factors, not only specific to the sector under consideration. It can be proved that $\mathbf{C}$ is not affected by intrasectoral outsourcing phenomena (Montresor \& Vittucci Marzetti, 2007). Furthermore, when $\mathbf{C}$ is built up by using total production flows (domestic plus imported), as we do in the present paper (unlike Momigliano \& Siniscalco, 1982), the relative indicators are also able to account for intersectoral international outsourcing. ${ }^{4}$

In synthesis, the outsourcing indicators one can use for structural change analysis are among them inherently diverse. As Table 1 shows, one should first consider whether she is interested in capturing the structural effects of inter rather than intrasectoral outsourcing. In the first case, service outsourcing is signaled, incontrovertibly but also somehow inaccurately, by an increase in the two sectoral ratios $S E R V_{i} / Q_{i}$ and $S E R V_{i} / L A B R_{i}$. A more comprehensive measure of it, instead, is provided by an increase in the weight of business sector services on the relative subsystem in terms of hours worked $\left(\sum_{k=m}^{n} c_{k i}\right)$ and a correlated decrease of the vertical integration degree of the same sector $\left(c_{i i}\right)$. On the contrary, subsystem measures do not capture intrasectoral outsourcing: $c_{i i}$ and $\sum_{k=m}^{n} c_{k i}$ are expected not to change. In this case, signals of outsourcing should instead come from both an increase in the autocoefficient of the relevant sector $\left(a_{i i}\right)$ and a decrease of the sectoral ratio $S E R V_{i} / Q_{i}$.

All the indicators are affected by a certain degree of inaccuracy. For this reason, they should be used, rather than alternatively, in a complementary way, by retaining their different signaling power. This is what we will do in the remainder of the paper. In particular, the indicators at the subsystem level $\left(c_{i i}\right.$ and $\sum_{k=m}^{n} c_{k i}$ ) will be mainly used in Section 3.1, while those at the sectoral level $\left(S E R V_{i} / Q_{i}, S E R V_{i} / L A B R_{i}\right.$ and $\left.a_{i i}\right)$ in Section 3.2. 
Table 1: Expected variations of the sector/subsystem indicators in manufacturing sector $i$

\begin{tabular}{|c|c|c|c|}
\hline Event & Level & Indicators & $\begin{array}{l}\text { Expected } \\
\text { variation }\end{array}$ \\
\hline \multirow{5}{*}{$\begin{array}{l}\text { Intersectoral } \\
\text { disintegration }\end{array}$} & Sector & $a_{i i}^{a}$ & $=/-\Delta$ \\
\hline & & $S E R V_{i} / Q_{i}{ }^{b}$ & $+\Delta$ \\
\hline & & $S E R V_{i} / L A B R_{i}{ }^{c}$ & $+\Delta$ \\
\hline & Subsystem & $c_{i i}^{d}$ & $-\Delta$ \\
\hline & & $\sum_{k=m}^{n} c_{k i}{ }^{e}$ & $+\Delta$ \\
\hline \multirow{5}{*}{$\begin{array}{l}\text { Intrasectoral } \\
\text { disintegration }\end{array}$} & Sector & $a_{i i}{ }^{a}$ & $+\Delta$ \\
\hline & & $S E R V_{i} / Q_{i}{ }^{b}$ & $-\Delta$ \\
\hline & & $S E R V_{i} / L A B R_{i}^{c}$ & $=$ \\
\hline & Subsystem & $c_{i i}^{d}$ & $=$ \\
\hline & & $\sum_{k=m}^{n} c_{k i}{ }^{e}$ & $=$ \\
\hline
\end{tabular}

\footnotetext{
${ }^{a}$ Autocoefficient of sector $i: a_{i i}=[\mathbf{A}]_{i i}=\left[\mathbf{Q} \hat{\mathbf{q}}^{-1}\right]_{i i}$, where $\mathbf{Q}$ is the matrix of sectoral intermediate consumption and $\hat{\mathbf{q}}$ the diagonalised vector of sectoral total production.

${ }^{b}$ Intermediate market services expenditure per production unit in sector $i$.

${ }^{c}$ Intermediate market services expenditure on labour compensation in sector $i$.

${ }^{d}$ Vertical integration of sector $i: c_{i i}=[\mathbf{C}]_{i i}=\left[\hat{\mathbf{I}} \mathbf{B}\left(\mathbf{l}^{\prime} \mathbf{B}\right)^{-1}\right]_{i i}$, where $\mathbf{l}^{\prime}$ is the row vector of labour inputs and $\mathbf{B}=\hat{\mathbf{q}}^{-1}(\mathbf{I}-\mathbf{A})^{-1} \hat{\mathbf{y}}$, with $\hat{\mathbf{y}}$ the diagonalised vector of final demand.

${ }^{e}$ Service integration in subsystem $i$ : row-sum of $\mathbf{C}$ for the business sector services.
}

\section{Outsourcing and structural change in a vari- able set of OECD countries}

In this section we apply the outsourcing measurements described in the previous one to some OECD countries over the ' 80 s and the middle '90, both at cross-sectional and inter-temporal level. Because of data availability, we will refer to two different country sets, that we will call, respectively: the OECD6, made up of Canada, Denmark, France, Japan, UK and US, over the '80s; the OECD18, that includes Australia, Canada, Check Republic, Denmark, Spain, Finland, France, Germany, Greece, Hungary, Italy, Japan, Korea, Netherlands, Norway, Poland, UK and US, with respect to the middle '90s (see Appendix A). ${ }^{5}$ 
Still because of data availability, we retained a disaggregation of 14 manufacturing sectors (including construction) for the OECD6, and of 17 sectors for the OECD18 (see Appendix B). ${ }^{6}$

\subsection{The subsystem level}

As we said before, the structural change implications of outsourcing can be caught at two levels of analysis: the subsystem and the sectoral level. Let us consider each of them in turn, starting from the more general.

\subsubsection{Vertical integration/disintegration over the '80s in the OECD6}

Although for a limited number of OECD countries, imposed by the use of IO tables at constant prices, Figure 1 and 2 show some interesting results.

First of all, the average value of $c_{i i}$ of the retained sectors shows in general a reversed U-shaped pattern of change over time: first increasing (in the early '80s) and then decreasing (in the late '80s). Outsourcing thus seems to have added to other disintegration determinants just in the last part of the decade, and to a different extent in different sectors. For the sake of illustration, just compare machinery \& equipment - on average, one of the most disintegrating sectors in the middle ' $80 \mathrm{~s}$ - with fabricated metal products - whose disintegration has been relatively less intense.

A relevant exception to this trend is transport equipment, including motorvehicles: the only sector whose average $c_{i i}$ is decreasing over the whole period, being it due to technological change or outsourcing.

Further insights can be obtained by analyzing the temporal changes occurred in $\sum_{k=m}^{n} c_{k i}$. Figure 3 and 4 show that, unlike vertical disintegration, service integration was already occurring in the early ' 80 s (with the only exception of residual manufacturing). It is worthwhile observing that the correlation between the rankings in terms of changes in $c_{i i}$ and in $\sum_{k=m}^{n} c_{k i}$ is positive $(+0.115)$, thus possibly hinting at a certain role of service outsourcing in driving vertical disintegration in the middle ' 80 s.

Going further these common trends, important country specificities emerge. Looking at manufacturing as a whole, in the UK business sector services were the most integrated in the manufacturing subsystem in 1990, while in 1980 


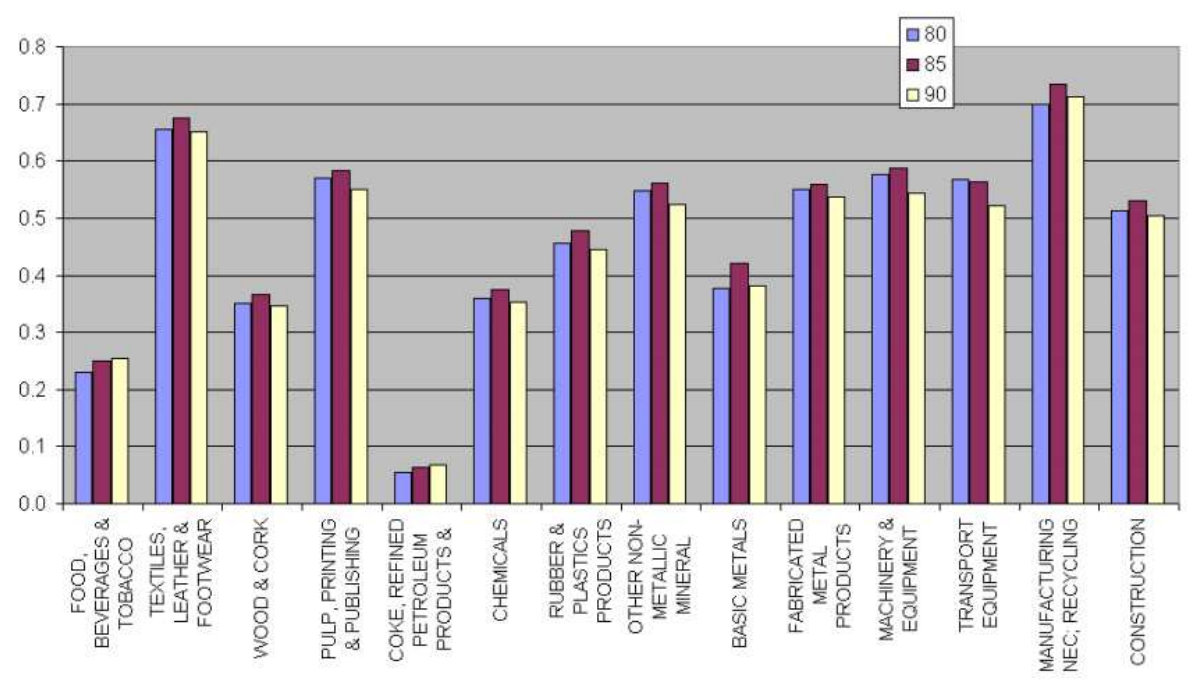

Figure 1: Vertical integration degree $\left(c_{i i}\right)$ of OECD6 manufacturing - crosscountry average values: 1980-1990

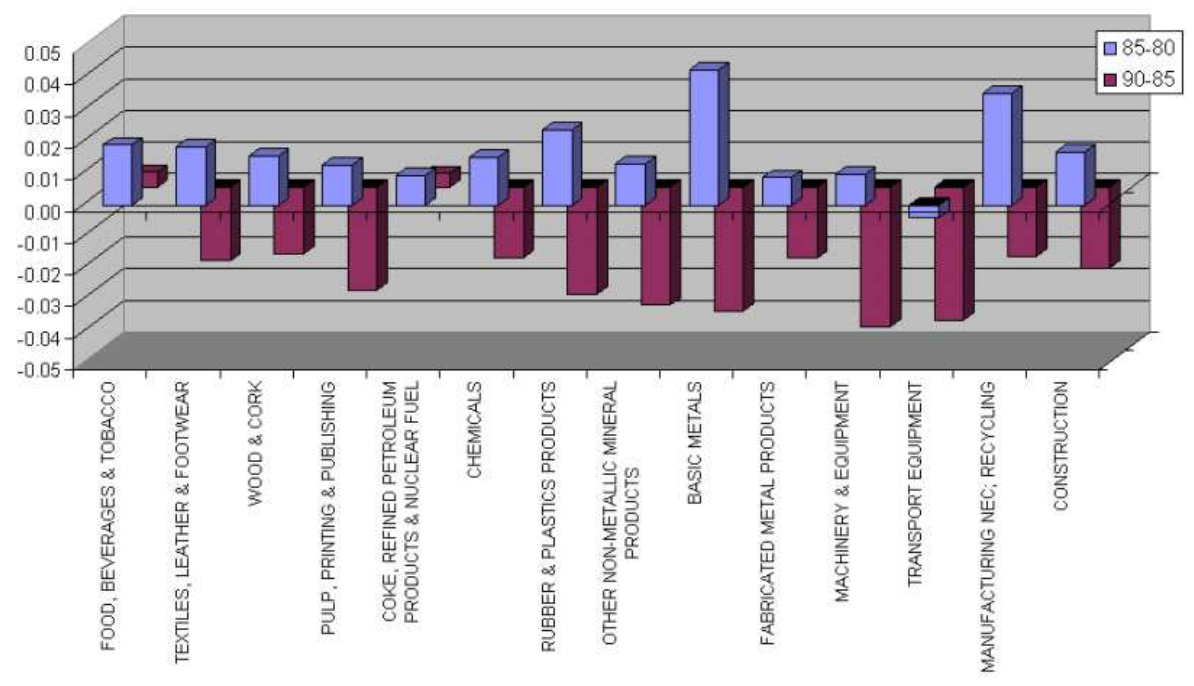

Figure 2: Vertical integration degree $\left(c_{i i}\right)$ of OECD6 manufacturing - changes in cross-country average values: 1980-1990 


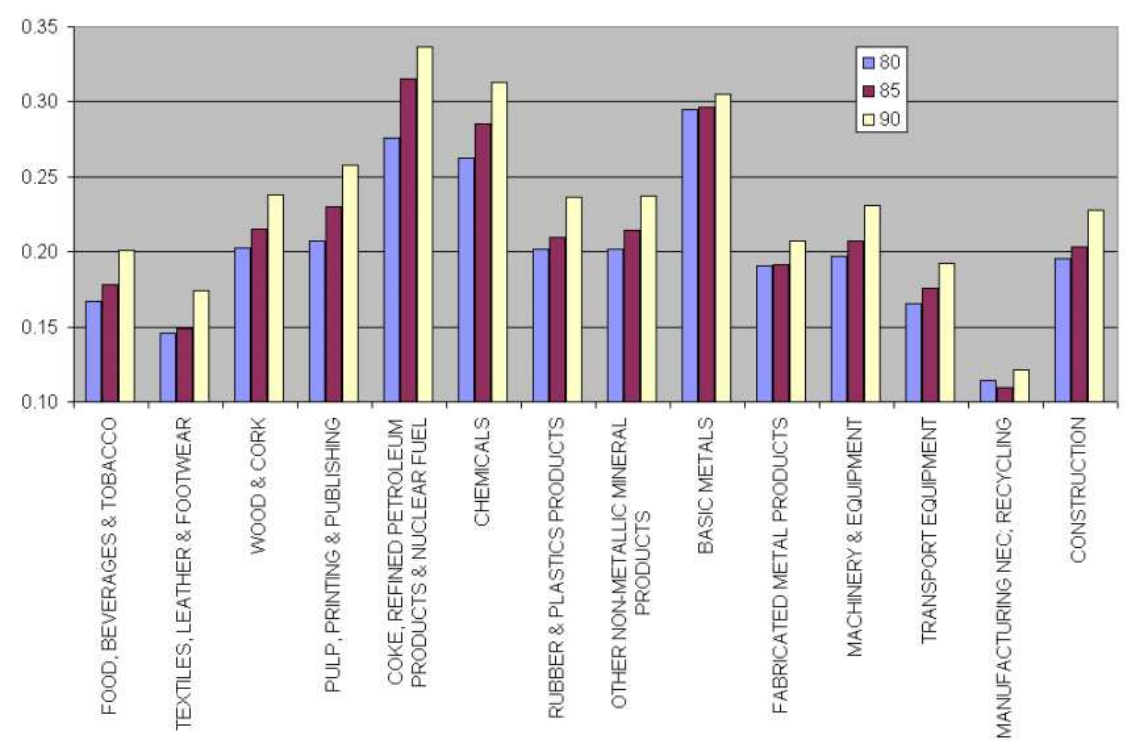

Figure 3: Service integration in manufacturing subsystems $\left(\sum_{k=m}^{n} c_{k i}\right)$ - crosscountry average values: 1980-1990

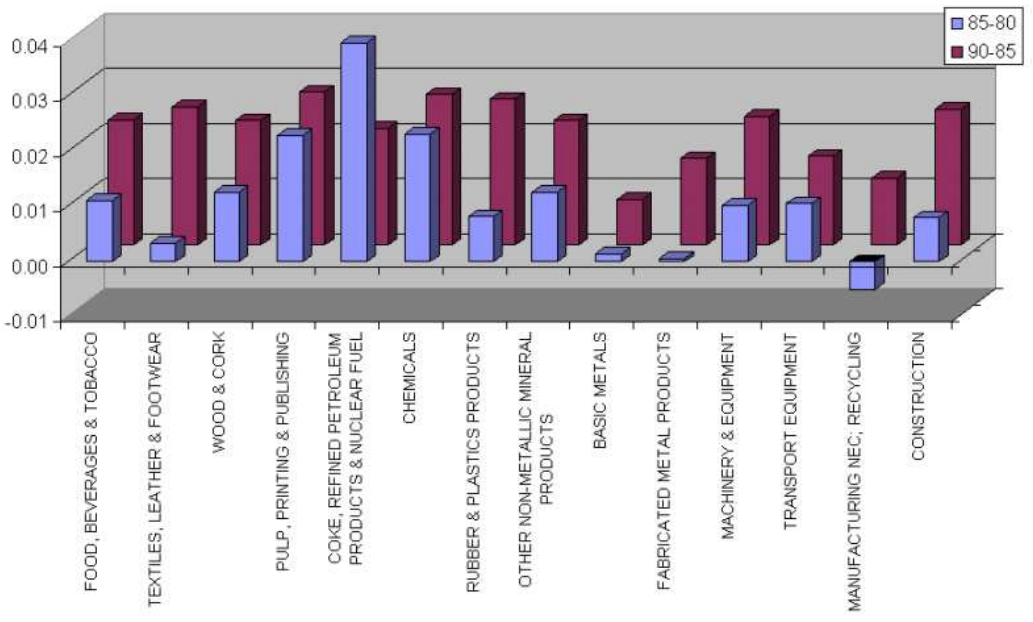

Figure 4: Service integration in manufacturing subsystems $\left(\sum_{k=m}^{n} c_{k i}\right)-$ changes in cross-country average values: 1980-1990 


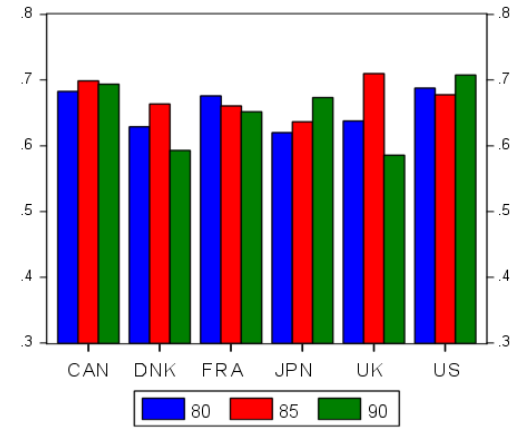

(a) Vertical integration degree $\left(c_{i i}\right)$

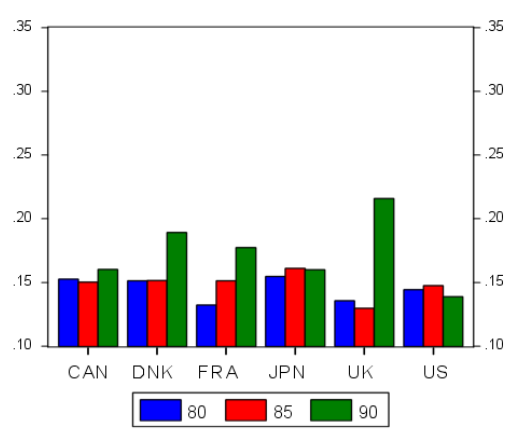

(b) Service integration $\left(\sum_{k=m}^{n} c_{k i}\right)$

Figure 5: Textiles, textile products, leather and footwear: 1980-1990

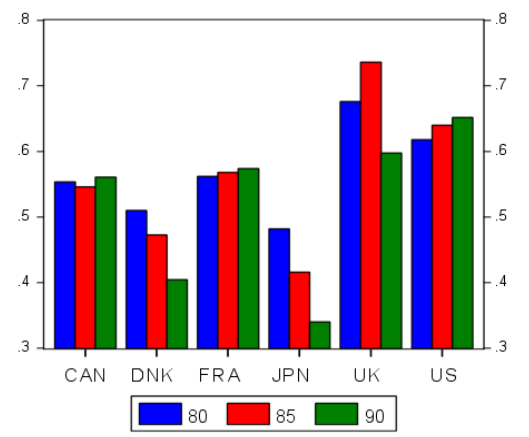

(a) Vertical integration degree $\left(c_{i i}\right)$

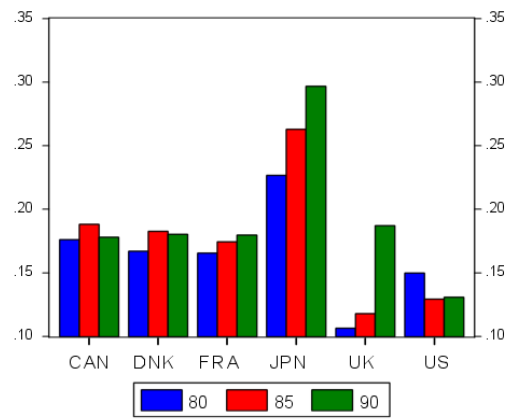

(b) Service integration $\left(\sum_{k=m}^{n} c_{k i}\right)$

Figure 6: Transport equipment: 1980-1990

they were the least integrated ones. In Japan, $\sum_{k=m}^{n} c_{k i}$ increased consistently only during the late ' 80 s and, what is more relevant, it was not accompanied by an appreciable vertical disintegration of the manufacturing sector. The US were the only country in which $\sum_{k=m}^{n} c_{k i}$ during the ' 80 s decreased, hinting at a different strategy of US manufacturing firms (the relative data are available from the authors at request).

Further inter-country differences emerge when we refer to two sectors of our disaggregation which are usually deemed more "vulnerable" to outsourcing: textiles (with leather \& footwear) and transport equipment.

As Figure 5 shows, during the '80s the $c_{i i}$ of the textile sector has progressively decreased, and the corresponding $\sum_{k=m}^{n} c_{k i}$ considerably increased, 
mainly in the European countries (Denmark, France and UK). For the nonEuropean countries (Canada, Japan and US), instead, these measures did not change significantly from the early to the late ' 80 s.

What seems to emerge as the "UK case" gets confirmed in other subsystems, and in particular in transport equipment (Figure 6). Accordingly, the large increase of service integration in the UK manufacturing subsystem shown by the data seems to support the hypothesis of an overestimation of the tertiarisation of the UK economy over the '80s due to an inaccurate resort to sectoral data (McCarthy \& Anagnostou, 2004; Vittucci Marzetti, 2008).

The analysis of transport equipment (Figure 6) also shows a notable disintegration of the Japanese sector, indeed the most disintegrated one over the whole period, far beyond the others, and with a recent increase in the disintegration ranking. Particularly interesting is the comparison with $c_{i i}$ in the US, both in terms of levels (in the '90s) and rates of change (from the early to the late '80s). These data seem thus to confirm the outcomes of the studies, mainly at firm level, on the Japanese transport equipment sector (e.g. Womack et al., 1990), as they show how the economic restructuring in this sector changed the contribution of the sector itself to the corresponding subsystem in terms of labour.

\subsubsection{Vertical integration/disintegration in the middle '90s in the OECD18}

By referring to the middle '90s, the previous integration/disintegration analysis can be carried out, using IO tables at current prices, with respect to a broader set of countries (Appendix A).

To start with, we worked out cross-country average values of $c_{i i}$ and $\sum_{k=m}^{n} c_{k i}$ for all the manufacturing sectors/subsystems. Table 2 classifies them into three groups, depending on the vertical integration degree being lower than 40\% (low vertical integration), in-between $40 \%$ and $50 \%$ (middle vertical integration) and higher than $50 \%$ (high vertical integration). ${ }^{7}$

The ranking points to five "suspect" sectors in terms of disintegration, that is: (i) coke, refined petroleum products and nuclear fuel; (ii) food products, beverages and tobacco; (iii) motor vehicles, trailers and semi-trailers; (iv) 
chemicals and chemical products; (v) basic metals. For the last three, the suspicious finds confirmation in other studies at the firm and industry level, which show that "buy" rather than "make" has become a dominant strategy for them (e.g. Piachaud, 2002; Bongart, 1993; Lieberman \& Johnson, 1999). Less expected was the result for the first two "resource intensive" sectors. However, the intersectoral approach to outsourcing we are following allows us to conclude that, for these two sectors, vertical disintegration represents quite a structural feature on the production side, not only directly linked to outsourcing or organizational factors. Indeed, they heavily rely on, respectively, the mining and the agricultural sectors (data available from the authors at request). A similar structural feature cannot be found instead in the subsystems of the other least integrated sectors, such as basic metals, chemical and transport equipment, for which no manufacturing or agricultural sector out of the main diagonal seems to play a pivotal role.

The "closeness" of one economic sector to those producing raw materials is thus an important, differentiating aspect of the level of vertical integration/disintegration of the firms operating in it. Once reported at the microeconomic level, this result appears particularly interesting, as it recovers in the analysis the importance of those production and technological aspects that the standard, new institutional accounts of outsourcing downplay in front of that of the organization and contracting ones. In this last respect, the IO analysis thus seems to support the complementary use of transaction costs and resource-competence-based views of vertical integration and disintegration that Jacobides \& Winter (2005), among the others, point as essential in understanding the "institutional structure of production".

Going back to our $c_{i i}$ results, and crossing them with those for $\sum_{k=m}^{n} c_{k i}$, further insights on the five "candidate" sectors can be obtained (Table 2). With the only exception of food, beverages and tobacco, the remaining four are subsystems in which market services are the most integrated in the middle '90s. Let us also observe that the two rankings with respect to the middle '90s are quite similar, supporting our tentative interpretation of a relationship between $c_{i i}$ and $\sum_{k=m}^{n} c_{k i}$ : the Spearman's rank correlation index is 0.684 and becomes 0.798 when the two "resource intensive" sectors previously analyzed are not considered. 
Table 2: Vertical integration $\left(c_{i i}\right)$ and service integration $\left(\sum_{k=m}^{n} c_{k i}\right)$ - middle '90s - cross-country average values

\begin{tabular}{|c|c|c|c|c|}
\hline \multirow[b]{2}{*}{ Sector/subsystem } & \multicolumn{4}{|c|}{ Avg $\%$ values } \\
\hline & $\begin{array}{l}\text { Vertical } \\
\text { integration }\end{array}$ & Rank & \multirow[t]{2}{*}{$\begin{array}{l}\text { Service } \\
\text { integration }\end{array}$} & Rank \\
\hline \multicolumn{4}{|l|}{ Low vertical integration } & \\
\hline Coke, refined petroleum products and nuclear fuel & 9.9 & 1 & 35.8 & 1 \\
\hline Food products, beverages and tobacco & 26.3 & 2 & 20.6 & 14 \\
\hline Motor vehicles, trailers and semitrailers & 35.1 & 3 & 28.4 & 4 \\
\hline Chemicals & 35.4 & 4 & 35.3 & 2 \\
\hline Basic metals & 37.4 & 5 & 30.2 & 3 \\
\hline \multicolumn{5}{|l|}{ Middle vertical integration } \\
\hline Rubber and plastics products & 44.2 & 6 & 25.7 & 7 \\
\hline Electrical machinery \& Apparatus, nec & 45.4 & 7 & 24.9 & 8 \\
\hline $\begin{array}{l}\text { Office and computing machinery - Communica- } \\
\text { tion equipment - Medical, precision and optical } \\
\text { instruments }\end{array}$ & 46.9 & 8 & 27.6 & 5 \\
\hline Other non-metallic mineral products & 48.5 & 9 & 26.3 & 6 \\
\hline Machinery and equipment, nec & 49.4 & 10 & 23.4 & 10 \\
\hline Other transport equipment & 49.6 & 11 & 21.2 & 13 \\
\hline Wood, products of wood and cork & 50.2 & 12 & 18.2 & 16 \\
\hline \multicolumn{5}{|l|}{ High vertical integration } \\
\hline Manufacturing, nec; Recycling & 52.2 & 13 & 19.4 & 15 \\
\hline Construction & 52.4 & 14 & 21.4 & 11 \\
\hline Pulp, paper, printing and publishing & 53.2 & 15 & 24.9 & 9 \\
\hline Fabricated metal products & 54.2 & 16 & 21.3 & 12 \\
\hline Textiles, textile products, leather and footwear & 64.6 & 17 & 17.8 & 17 \\
\hline
\end{tabular}

Source: our calculation on OECD I-O Database and 60-Industries GGDC Database, 2005. 
Apart from these last two sectors, some remarks should be made about the other ones that exhibit both low $c_{i i}$ and high $\sum_{k=m}^{n} c_{k i}$ : motor vehicles, chemicals and basic metals. With respect to the first, due to the long value chain characterizing its production processes, as well as the large resort to outsourcing pointed out in many case-studies (e.g. Womack \& Jones, 1994), this result is not surprising. And this holds true also for chemicals, in which service outsourcing practices are widespread, in particular as far as R\&D activities are concerned (e.g. Howells, 1999). The ranking of basic metals is instead somehow counterfactual, given that, on the basis of the relative "closeness" to raw materials, we would have expected a relative high $c_{i i}$. The prominent role of horizontal linkages over the vertical ones for manufacturing, together with the high value of $\sum_{k=m}^{n} c_{k i}$ in the basic metal subsystem, thus seems to suggest a process of change far beyond its structural nature.

Looking at the changes occurred over time in the levels of $c_{i i}$, Table 3 compares the ranking of the considered manufacturing sectors in terms of average $c_{i i}$ in the early ' $80 \mathrm{~s}$, late ' $80 \mathrm{~s}$ and middle '90s. With respect to the restricted set of countries we analyzed in Section 3.1.1 (OECD6), apart from some notable exceptions, the ranking of the retained sectors in terms of $c_{i i}$ represents quite a stable feature. In spite of all the relevant technological, organizational and demand changes occurred in the period, the "club" of the most disintegrated sectors remains substantially unaltered: coke, refined petroleum products and nuclear fuel; food products, beverages and tobacco; chemicals and chemical products; and basic metals are the subsystems on which the correspondent sector weights relatively less in all the three periods. However, two important structural changes can be noticed, although still on average. First of all, the disintegration process of the transport equipment sector, already detected above, has brought it progressively from, on average, one of the most integrated (in the early ' 80 s) to one of the least integrated ones (in the middle '90s), and the change seems to have occurred at an increasing rate.

Second, in approaching the middle '90s the construction sector seems to have been affected by an opposite phenomenon. More gradual changes over the period can be observed in non-metallic mineral products, fabricated metal products and in machinery equipment. Quite interestingly, while the 
Table 3: Vertical integration degree $\left(c_{i i}\right)$ of OECD6 manufacturing sectors: 1980-1995

\begin{tabular}{|c|c|c|c|c|c|c|c|}
\hline \multirow{2}{*}{ Code } & \multirow{2}{*}{ Sector } & \multicolumn{2}{|c|}{ early '80s } & \multicolumn{2}{|c|}{ early '90s } & \multicolumn{2}{|c|}{ mid-'90s } \\
\hline & & Avg & Rank & Avg & Rank & Avg & Rank \\
\hline 23 & $\begin{array}{l}\text { Coke, refined petroleum products } \\
\text { and nuclear fuel }\end{array}$ & 5.3 & 1 & 6.8 & 1 & 10.4 & 1 \\
\hline $15-16$ & $\begin{array}{l}\text { Food products, beverages and to- } \\
\text { bacco }\end{array}$ & 23.0 & 2 & 25.4 & 2 & 29.1 & 2 \\
\hline 20 & Wood and products of wood and cork & 35.0 & 3 & 34.5 & 3 & 49.7 & 6 \\
\hline 24 & Chemicals & 35.9 & 4 & 35.2 & 4 & 35.6 & 3 \\
\hline 27 & Basic metals & 37.5 & 5 & 38.0 & 5 & 42.7 & 4 \\
\hline 25 & Rubber and plastics products & 45.4 & 6 & 44.4 & 6 & 49.9 & 7 \\
\hline 45 & Construction & 51.2 & 7 & 50.4 & 7 & 53.2 & 11 \\
\hline 26 & Other non-metallic mineral products & 54.6 & 8 & 52.2 & 9 & 52.9 & 10 \\
\hline 28 & Fabricated metal products & 54.8 & 9 & 52.2 & 10 & 57.8 & 13 \\
\hline $34-35$ & Transport equipment & 56.7 & 10 & 52.2 & 8 & 44.2 & 5 \\
\hline $21-22$ & Pulp, paper, printing and publishing & 56.8 & 11 & 54.8 & 12 & 57.6 & 12 \\
\hline $29-33$ & Machinery and equipment & 57.6 & 12 & 54.2 & 11 & 52.8 & 9 \\
\hline $17-19$ & $\begin{array}{l}\text { Textiles, textile products, leather } \\
\text { and footwear }\end{array}$ & 65.6 & 13 & 65.1 & 13 & 66.9 & 14 \\
\hline $36-37$ & Manufacturing, nec; Recycling & 69.8 & 14 & 71.2 & 14 & 51.6 & 8 \\
\hline
\end{tabular}

Source: our calculation on OECD I-O Database and 60-Industries GGDC Database, 2005. 
Table 4: Service integration in the manufacturing subsystem $\left(\sum_{k=m}^{n} c_{k i}\right)-$ middle '90s

\begin{tabular}{lc}
\hline Country & Service integration \\
\hline United Kingdom & 29.1 \\
Netherlands & 29.0 \\
France & 28.9 \\
Australia & 26.9 \\
United States & 25.7 \\
Canada & 25.4 \\
Norway & 25.1 \\
Spain & 24.9 \\
Korea & 24.2 \\
Finland & 23.5 \\
Italy & 23.3 \\
Japan & 22.9 \\
Germany & 22.5 \\
Czech Republic & 21.8 \\
Poland & 21.4 \\
Denmark & 20.3 \\
Greece & 19.1 \\
Hungary & 15.2 \\
\hline
\end{tabular}

Source: our calculation on OECD I-O Database and 60-Industries GGDC Database, 2005.

former two, typically specialized-supplier sectors, have scaled positions in terms of $c_{i i}$, the latter, encompassing also computing machinery, have scaled the integration ladder down, pointing to a possible evidence of the outsourcing processes occurred in it. ${ }^{8}$

Shifting from a sector to a country perspective, it is interesting to note that, out of the 18 OECD countries of the present set, business sector services have a relatively lower integration in manufacturing in all the transition economies considered, namely Czech Republic, Poland and Hungary (Table $4)$.

This fact appears quite interesting considering that these countries underwent a tertiarisation process by which their employment reached, in the middle '90s, a structure quite similar to that of the EU countries (e.g. Lan- 
desmann, 2000). Among them, Hungary deserves a particular attention. As Landesmann's (2000) survey on the European post-socialist countries clearly shows, this is the country in which in the '90s there was the largest increase in the service share, both in terms of value added and labour, and where manufacturing labour productivity grew faster. Nevertheless, in this country business sector services are the least integrated in manufacturing, thus suggesting that the increase in the service sector was mainly due to consumer services, whereas the producer services still lag behind.

It is worthwhile noticing that the country ranking we got in terms of $\sum_{k=m}^{n} c_{k i}$ is somewhat different from that obtained working with $S E R V_{i} / Q_{i}$ and $S E R V_{i} / L A B R_{i}$. In particular, these data lead to a significant underestimation for some countries, namely, France, Netherlands, Finland and Poland, in which producer services appear more important than final ones. On the contrary, the same data overestimate the integration of services in manufacturing with respect to Greece and Hungary, possibly because of the prominent role of final services in producer ones (data available from the authors at request).

In concluding, it could be interesting to analyze the most recent integrationdisintegration patterns occurred in the "usual suspect" manufacturing sectors: textiles, leather \& footwear, and transport equipment (Figure 7).

In general, the low value of $\sum_{k=m}^{n} c_{k i}$ for the former socialist European countries, and for Hungary in particular, gets confirmed in both the two sectors. Confirmed is also the high value of $\sum_{k=m}^{n} c_{k i}$ in France, UK and Netherlands, as well as the reversing trend of it in the US (see Figures 5-6). As for the other countries, it is interesting to note the close ranking of Japan and Korea, both in terms of $c_{i i}$ and of $\sum_{k=m}^{n} c_{k i}$, especially in transport equipment and machinery \& equipment.

Trying to have a closer look at each sector, the analysis of textiles reveals the low value of $\sum_{k=m}^{n} c_{k i}$ in the Italian subsystem, whose recent delocalisation strategies are well-known. ${ }^{9}$ For the transport equipment sector, what emerges is the marked distance of Germany, Italy, Spain from the disintegrated model characterizing France, UK, Japan and US, thus suggesting institutional idiosyncrasies in the organisation of the relative subsystem. 


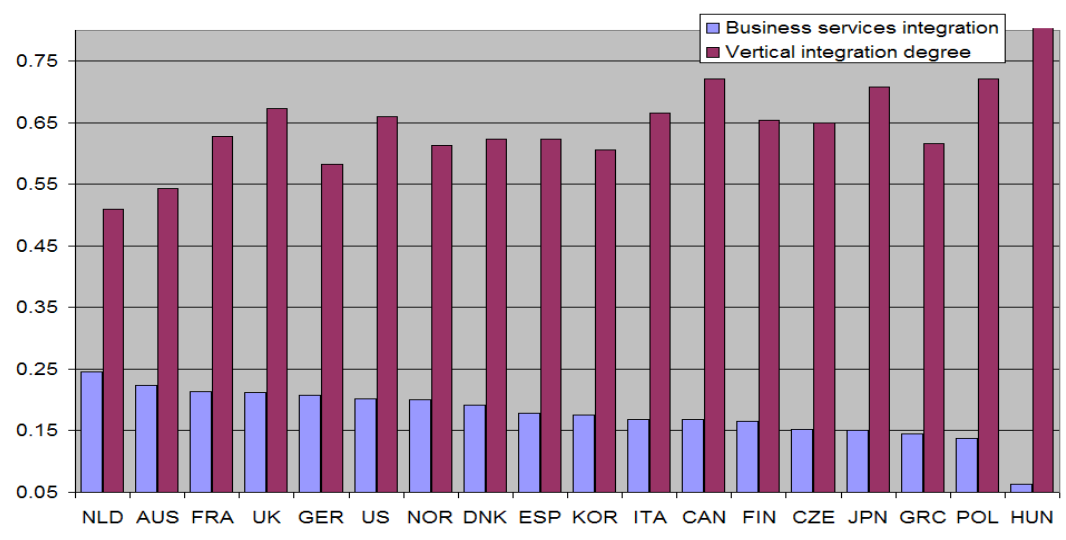

(a) Textiles, textile products, leather and footwear

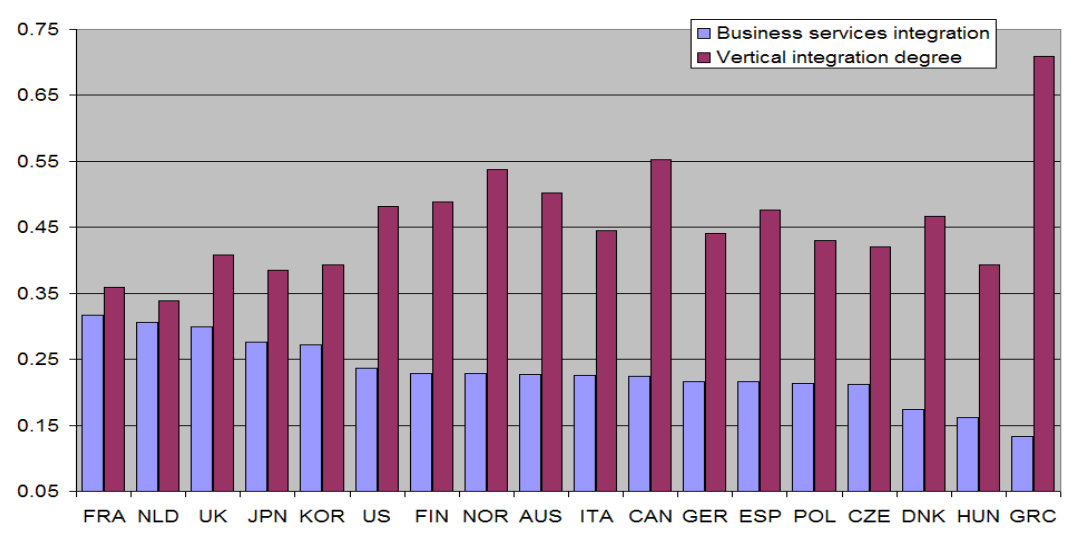

(b) Transport equipment

Figure 7: Vertical integration degree $\left(c_{i i}\right)$ and service integration $\left(\sum_{k=m}^{n} c_{k i}\right)$ middle '90s

\subsection{The sectoral level}

As we have argued, the subsystem and the sectoral level of analysis should be regarded as complementary. While the former takes into account the overall changes occurred in intersectoral production linkages due to externalizations practices, the latter is suitable for mapping firms' outsourcing strategies.

For a more straightforward comparison, we have calculated the outsourcing indicators at the sectoral level for the same countries of Section 3.1.1 and with respect to the usual "candidate" sectors, namely textiles, leather \& footwear, and transport equipment. Figures 8 and 9 show the results of this analysis 


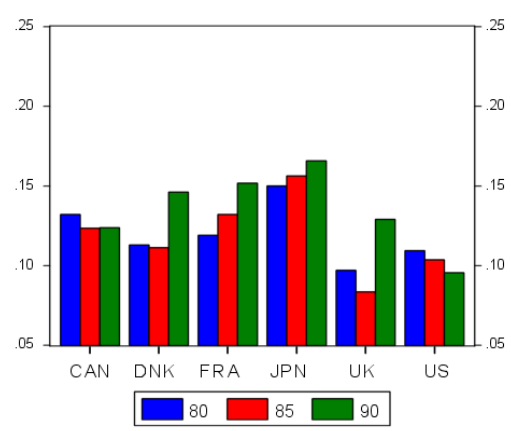

(a) Textiles

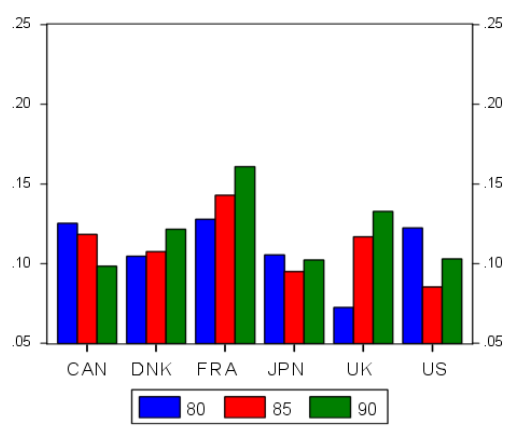

(b) Transport Equipment

Figure 8: Intermediate business sector services expenditure per production unit in manufacturing $(S E R V / Q)$ (constant prices): 1980-1990

with respect to the ' 80 s.

At the outset, let us observe that, while France registers the highest average levels of both $S E R V / Q$ and $S E R V / L A B R$, the UK shows their highest growth rates: for manufacturing as a whole, for example, $S E R V / Q$ increased more than $66 \%$, while $S E R V / L A B R$ by $60.6 \%$. Data thus provide further evidence of the economic restructuring of the UK manufacturing sector during the '80s, and especially in the last five years. At the same time, they seem to point to a possible "European model of externalisation", given that for the European countries the two data series are quite consistent between them and decisively supportive of the outsourcing hypothesis for all the considered sectors. Finally, crossing these data with those on the service integration in manufacturing subsystems (Section 3.1.1), an interesting fact should be noticed: the service integration in UK manufacturing, usually retained a systemic feature resulting from the complex interactions of technological and organizational factors in the overall system, appears largely underestimated by the two indicators of the present Section, both in terms of levels and of rates of changes, as it clearly emerges comparing Figures 5-6 with Figures 8-9.

As far as Canada and the US are concerned, the sectoral data do not show significant tendencies toward service outsourcing in any of the considered sectors. In particular, in the US during the '80s the overall rate of change 


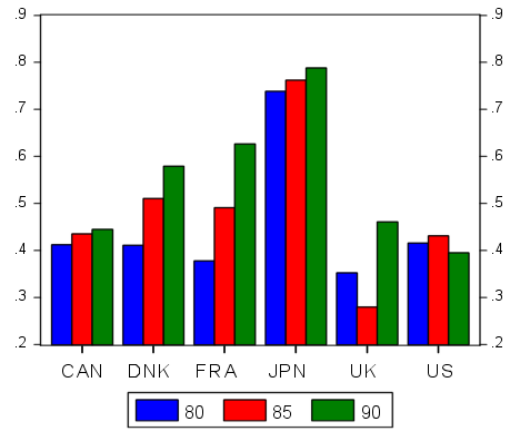

(a) Textiles

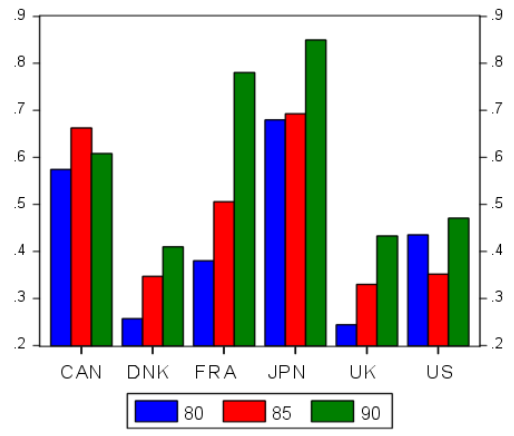

(b) Transport Equipment

Figure 9: Intermediate business sector services expenditure on labour compensation (current prices) (SERV/LABR): 1980-1990

of $S E R V / Q$ for the whole manufacturing is negative $(-5.2 \%)$, whereas the rate of change of $S E R V / L A B R$, though positive, is relatively small (6.9\%). The only exception is the US transport equipment sector in the late ' 80 s, with respect to which $S E R V / Q$ and $S E R V / L A B R$ possibly hint at a certain rethinking of the insourcing strategies followed in the early ' 80 s by the US firms. Indeed, after a marked decrease of $S E R V / Q$ and $S E R V / L A B R$ for the sector between 1980 and 1985 (respectively, $-30.3 \%$ and $-19.2 \%$ ) both the indicators considerably increased in the late ' 80 s $(+20.7 \%$ and $+33.9 \%)$. Quite interestingly, this fact involved neither an increase of service integration in the transport equipment subsystem, nor a vertical disintegration of the relative sector for the US (Figure 6).

Finally, special attention should be paid to the case of Japan, and of the Japanese transport equipment sector in particular, for which the picture is somehow mixed-up. On the one hand, we have a small and decreasing $S E R V / Q$, that seems to exclude service outsourcing in the sector, coupled with the fact that the average level of $S E R V / Q$ over the ' 80 s is particularly small for transport equipment. ${ }^{10}$ On the other hand, a large and increasing $S E R V / L A B R$ could lead to an opposite conclusion, in particular once crossed with an increasing service integration in the relative subsystem. The indicator increased a lot also for machinery \& equipment $(+35.4 \%)$, the main supplier sector of transport equipment. Furthermore, looking at the average levels of 


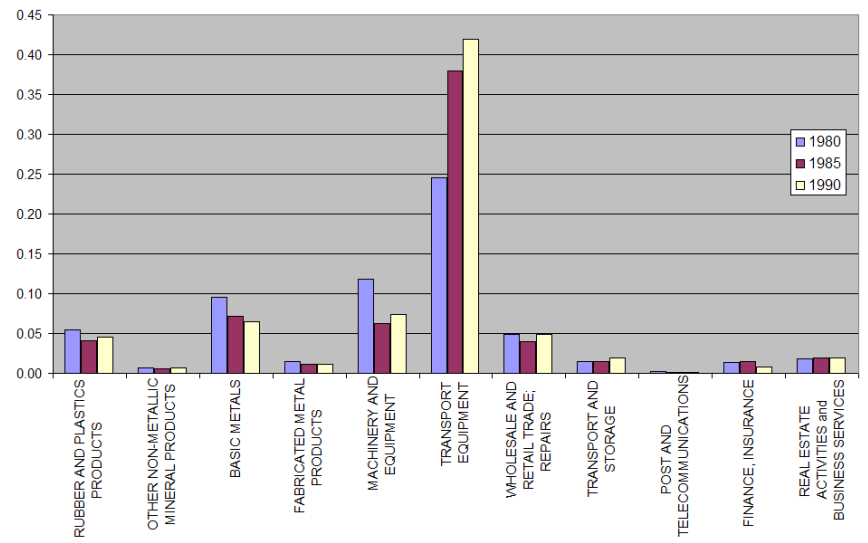

(a) Japan

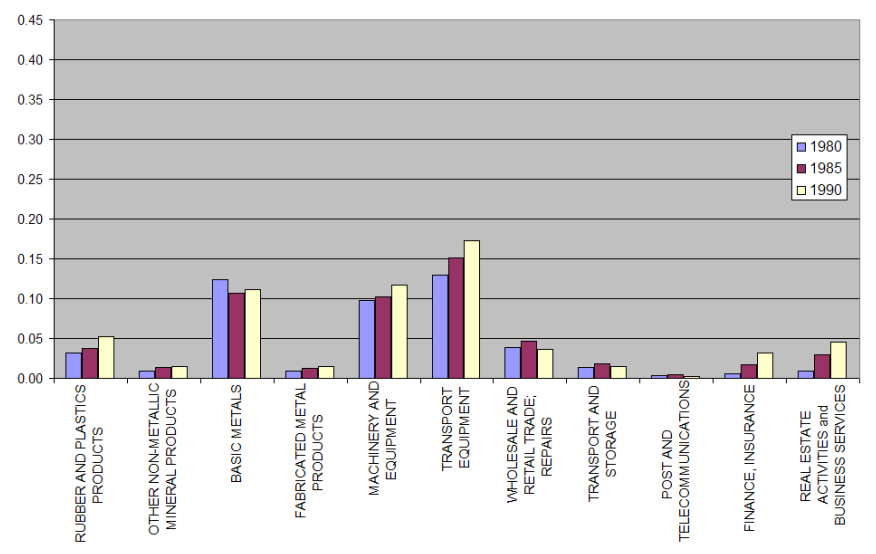

(b) United Kingdom

Figure 10: IO coefficients $\left(a_{i i}\right.$ and $\left.a_{i j}\right)$ in transport equipment (constant prices): 1980-1990

the indicators in the two sectors, Japan shows the highest values. In synthesis, it seems that the Japanese economic restructuring, while reflected in the changes occurred in the employment structure, does not result from the data on intermediate service consumptions per production unit.

This apparent inconsistency seems to be due to the intrasectoral nature of the outsourcing patterns of the Japanese transport sector. Indeed, as we said, in case of intrasectoral outsourcing $S E R V / Q$ would tend to decrease in the outsourcing sector $i$, whereas its $S E R V / L A B R$ would be, ceteris paribus, hardly affected. What is more, all the IO coefficients of the same sector tend 
to decrease, with the exception of the $a_{i i} \mathrm{~s}$, which, on the contrary, increase. Consistent changes can be observed in the present case where, over the ' $80 \mathrm{~s}$, the relative $a_{i i}$ s increased by $70.9 \%$, while, among the remaining five countries of the OECD6 set, the largest increase occurred in the UK and was of just $32.9 \%$ (Figure 10). ${ }^{11}$ At the same time, all the remaining $a_{i j} \mathrm{~s}$, in particular those referred to basic metals, machinery \& equipment and fabricated metal products, three of the most important and complementary inputs in the production of transport equipment. Over the ' $80 \mathrm{~s}$, in all the countries but Japan the reduction in the $a_{i j}$ of basic metals was accompanied by an increase for machinery \& equipment and fabricated metal products. On the contrary, in Japan they all decreased: $-31.4 \%$ for basic metals, $-37.3 \%$ for machinery $\&$ equipment and $-22.7 \%$ for fabricated metal products. One might argue that these results, rather than by disintegration, are mainly due to technical progress. However, if it was so, how to explain the marked increase of the autocoefficients $\left(a_{i i}\right)$ ?

A certain intrasectoral disintegration of the Japanese transport equipment sector appears therefore more than arguable and it is consistent with the data on employees per establishment in the automobile industry (Williams et al., 1998, p.25). Of course, other factors might have played a role in explaining the detected inconsistency. First of all, the particular relationships ("keiretsu") between the "outsourcee" firms and the "outsourcer" ones (e.g. Domberger, 1998) might have made input prices more similar to intra-firm "transfer prices" rather than to normally negotiated "market prices" (see, for instance, Jarillo, 1993), and then led to an underestimation of the service inputs of manufacturing sectors. Second, a certain increase in the service labour share of the transport equipment subsystem might have been due to the large labour productivity gains reached in the transport equipment during the '80s in Japan, not accompanied by an equal increase of labour productivity in the service sectors. In other words, the observed changes in the sectoral labour shares might have been also due to the different growth rates of sectoral productivity. However, although more than plausible, all these interpretations turn out to be complementary, rather than primary, with respect to the particular disintegration hypothesis we have put forward. 


\section{Final remarks and policy implications}

The paper argues that outsourcing and structural change are closely interconnected. While shifting firms' boundaries, or making them more permeable to market mechanisms, outsourcing inevitably shifts also sectoral boundaries. The organizational and the structural changes it determines are thus nothing but two coins of the same medal.

An effective bridging of outsourcing and structural change analysis has been hampered so far by different reasons. However, recent developments have made these obstacles less binding and made the investigation of the structural change implications of outsourcing more feasible.

On this basis, the paper tries to show how outsourcing, along with other determinants, might have reshaped the economic structure of some OECD economies over the '80s and the middle '90s. We have built a "battery" of indicators and carried out cross-country and temporal analyses to identify structural differences and patterns of change related to outsourcing.

A subsystem analysis has been contrasted to the standard sectoral analysis of service outsourcing, typically carried out in terms of intermediate market services expenditure on output and labour compensation.

Some of the results are supportive of evidences other contributions find through case-studies and/or nation specific analysis, such as the idiosyncratic resort to service outsourcing of the UK manufacturing sectors. Other results are, instead, quite original, such as the low degree of integration of services in manufacturing revealed by the post-socialist countries over the '90s, that helps better qualifying the massive process of tertiarisation they underwent.

Our analysis has some important policy implications. First of all, as shown in other studies (e.g. Dietrich, 1999; McCarthy \& Anagnostou, 2004), investigating the structural change implications of outsourcing might help in getting rid of wrong signals in orienting policies of industrial development. Without considering the intersectoral networks of production relationships that service outsourcing creates, the decline of manufacturing with respect to services might be overestimated: the tertiarisation of the former socialist countries, for example, should be better qualified in the light of the present study. 
Second, the structural change analysis of outsourcing could be helpful in better orienting trade policies. If the actual extent of service integration in manufacturing due to outsourcing is not recognized, the impact of manufactured goods imports on the domestic economy might be undervalued: the evaluation of the internal sustainability of the domestic UK economy, for example, could benefit from the results of the present paper.

Third, bridging outsourcing and structural change analysis might have an important role in driving industrial policies aimed at fostering productivity. The effects outsourcing produces by changing firm boundaries are well-known in productivity analysis, where it is now clear that outsourcing can in fact influence value added-based Total Factor Productivity (TFP) measures (e.g. Balk, 2003). The notable debate on the technology and TFP "race" between US and Japan, for example, should be informed by the different outsourcing strategies that seem to emerge for them from our study, in particular in such key sectors as transport equipment.

Last but not least, the direct and indirect relationships fueled by outsourcing processes should be retained in evaluating their employment effects and the relative employment policies. The different outsourcing patterns the paper shows between European and non-European countries, for example, could add important elements in better appreciating the different performances of their labour market. 


\section{A Country coverage}

\begin{tabular}{|c|c|c|c|c|}
\hline \multirow[t]{2}{*}{ Country } & \multicolumn{4}{|c|}{ Input-Output Tables } \\
\hline & early ' $80 \mathrm{~s}^{*}$ & mid-'80s* & early '90s* & mid-'90s \\
\hline Australia & & & & 1995 \\
\hline Canada & 1981 & 1986 & 1990 & 1997 \\
\hline Czech Republic & & & & 1995 \\
\hline Denmark & 1980 & 1985 & 1990 & 1997 \\
\hline Finland & & & & 1995 \\
\hline France & 1980 & 1985 & 1990 & 1995 \\
\hline Germany & & & & 1995 \\
\hline Greece & & & & 1994 \\
\hline Hungary & & & & 1998 \\
\hline Italy & & & & 1992 \\
\hline Japan & 1980 & 1985 & 1990 & 1995 \\
\hline Korea & & & & 1995 \\
\hline Netherlands & & & & 1995 \\
\hline Norway & & & & 1997 \\
\hline Poland & & & & 1995 \\
\hline Spain & & & & 1995 \\
\hline United Kingdom & 1979 & 1984 & 1990 & 1998 \\
\hline United States & 1982 & 1985 & 1990 & 1997 \\
\hline
\end{tabular}

*Input-output tables at constant prices 


\section{B Sector classification}

\begin{tabular}{lc}
\hline Sector & ISIC Rev.3 Codes \\
\hline Food products, beverages and tobacco & $15-16$ \\
Textiles, textile products, leather and footwear & $17-19$ \\
Wood and products of wood and cork & 20 \\
Pulp, paper, paper products, printing and publishing & $21-22$ \\
Coke, refined petroleum products and nuclear fuel & 23 \\
Chemicals & 24 \\
Rubber and plastics Products & 25 \\
Other non-metallic mineral products & 26 \\
Basic metals & 27 \\
Fabricated metal products & 28 \\
Machinery \& equipment & \\
...Machinery and equipment, nec & 29 \\
...Office and computing machinery - communication & $30,32-33$ \\
equipment - medical, precision and optical instruments & \\
...Electrical machinery and apparatus, nec & 31 \\
Transport equipment & \\
...Motor vehicles, trailers and semitrailers & 34 \\
...Other transport equipment & 35 \\
Manufacturing, nec; Recycling & $36-37$ \\
Construction & 45 \\
\hline
\end{tabular}




\section{Notes}

${ }^{1}$ Some results of this application have been sketched in another work of ours (Montresor \& Vittucci Marzetti, 2007) in order to show how the same measurements work in practice.

${ }^{2}$ Using micro data for 5 OECD countries, Pilat \& Wölfl (2005) show that the employment and revenues shares of manufacturing and services using establishment and enterprise based classifications are fairly similar.

${ }^{3}$ These concepts have been analytically studied since the late 1960 (see, for instance, Zaghini, 1967; Pasinetti, 1973) and mainly applied to empirical studies on productivity (e.g. Gupta \& Steedman, 1971; Milberg, 1991; De Juan \& Febrero, 2000).

${ }^{4}$ Their construction requires in this case a more articulated interpretation for the multiplication between labour input coefficients and the Leontief inverse. Furthermore, the invariance of $\mathbf{C}$ to relative price changes does not hold anymore (see Montresor \& Vittucci Marzetti, 2007).

${ }^{5}$ We will discuss only the results of total flows-based measures, as they enable us to take into account international outsourcing. However, the analysis of the domestic flowsderived measures leads to similar results. The interested reader can refer to Montresor \& Vittucci Marzetti (2006).

${ }^{6}$ To minimise distortions coming from sectoral aggregation, calculations have been carried out at the maximum level of disaggregation, and the results then reaggregated.

${ }^{7}$ The boundaries of the three intervals are somehow arbitrary and just used to better underline differences among sectors.

${ }^{8} \mathrm{As}$ for the wood and cork sector, the observed shift between the ' $80 \mathrm{~s}$ and the middle '90s might have been affected by a change in the classification from ISIC Rev.2 to ISIC Rev.3.

${ }^{9}$ The high vertical integration degree of Italy, instead, is not significant because this indicator is not affected by "intrasectoral disintegration", both within and across national boundaries.

${ }^{10}$ Service expenditure per production unit did not increase significantly in its traditional supplier sectors either, i.e. machinery \& equipment, basic metals, rubber and plastics products and other fabricated metal products. Although sectoral input flows at constant prices from business sector services increased more than $89.8 \%$, the overall increase in sectoral gross production was $95.6 \%$, thus determining a reduction in the coefficients of $-2.94 \%$.

${ }^{11} \mathrm{It}$ is worth noting that the increase in $a_{i i}$ we register in Japan is due neither to changes in the composition of the sector nor to the reorganisation of production across national boundaries. On the one hand, by increasing the level of disaggregation the basic insights get confirmed: the growth rate of motor vehicles, trailers and semitrailer in Japan was of $52.7 \%$, whereas in the UK it was of just $12.9 \%$. On the other hand, domestic flows-based autocoefficients in the Japanese transport equipment sector over the ' 80 s increased by $71 \%$, almost the same as total flows-based ones. 


\section{References}

Acemoglu, D. et al. (2002) Vertical integration and distance to frontier, Working Paper 9191, NBER.

Baldone, S. et al. (2002) EU Enlargement to the CEECs: Trade Competition, Delocalisation of Production, and Effects on the Economies of the Union (Milan: Franco Angeli).

Balk, M. (2003) On the relation between gross-output and value-added based productivity measures: The importance of the Domar factor, Working paper, Centre for Applied Economic Research.

Becker, M. C. \& Zirpoli, F. (2009) An organizational approach to the design of firm boundaries, Economia Politica, 3.

Bongart, A. (1993) The automotive industry: supply relations in contexts, in: H. de Jong (Ed), The Structure of European Industry, pp. 147-161 (London: Kluwer Academic Publishers).

De Juan, O. \& Febrero, E. (2000) Measuring productivity from vertically integrated sectors, Economic Systems Research, 12(1), pp. 65-82.

Dietrich, M. (1999) Explaining economic restructuring: an input-output analysis of organisational change in the European Union, International Review of Applied Economics, 13(2), pp. 219-240.

Domberger, S. (1998) The Contracting Organization. A Strategic Guide to Outsourcing (Oxford: Oxford University Press).

Gereffi, G. (2003) The governance of global value chains, Review of International Political Economy, forthcoming.

Ginzberg, E. \& Vojta, G. (1981) The service sector of the U.S. economy, Scientific American, 3.

Gorg, H. \& Hanley, A. (2004) Does outsourcing increase profitability, The Economic and Social Review, 35(3), pp. 267-288. 
Gupta, S. \& Steedman, I. (1971) An input-output study of labour productivity in UK, Oxford Bulletin of Economics and Statistics, 33, pp. 21-34.

Howells, J. (1999) Research and technology outsourcing and innovation systems: an exploratory analysis, Industry and Innovation, 6(2), pp. 111-129.

Humphrey, J. \& Schmitz, H. (2002) How does insertion in global value chains affect upgrading in industrial clusters, Regional Studies, 36, pp. 1017-1027.

Jacobides, M. G. \& Billinger, S. (2005) Designing the boundaries of the firm: from "make, buy or ally" to the dynamic benefits of vertical architecture, London Business School - Strategic and International Management Working Paper Series, working Paper.

Jacobides, M. G. \& Winter, S. G. (2005) The co-evolution of capabilities and transaction costs: Explaining the institutional structure of production, Strategic Management Journal, 26, pp. 395-413.

Jarillo, J. (1993) Strategic Networks: Creating the Borderless Organization (Oxford: Butterworth-Heinemann).

Jones, R. W. \& Kierzkowski, H. (2001) A framework for fragmentation, in: S. W. Arndt \& H. Kierzkowski (Eds), Fragmentation: New production patterns in the world economy, pp. 17-34 (Oxford and New York: Oxford University Press).

Kohler, W. (2004) Aspects of international fragmentation, Review of International Economics, 12(5), pp. 793-816.

Landesmann, M. (2000) Structural change in the transition economies, 19891999, Economic Survey of Europe, 2/3, pp. 95-123.

Lieberman, M. B. \& Johnson, R., Douglas (1999) Comparative productivity of japanese and u.s. steel producers, 19581993, Japan and the World Economy, 11(1), pp. 1-27.

McCarthy, I. \& Anagnostou, A. (2004) The impact of outsourcing on the transaction costs and boundaries of manufacturing, International Journal of Production Economics, 88, pp. 61-71. 
McFetridge, D. G. \& Smith, D. A. (1988) The Economics of Vertical Disintegration (Vancouver: Fraser Institute).

Milberg, W. S. (1991) Structural change and international competitiveness in Canada: an alternative approach, International Review of Applied Economics, 5, pp. 77-93.

Miller, R. E. \& Blair, P. D. (1985) Input-Output Analysis: Foundations and Extensions (New Jersey: Princeton-Hall).

Momigliano, F. \& Siniscalco, D. (1982) The growth of service employment: a reappraisal, BNL Quarterly Review, 142, pp. 269-306.

Montresor, S. \& Vittucci Marzetti, G. (2006) Outsourcing and structural change: Shifting firm and sectoral boundaries, Working Paper 566, Department of Economics, University of Bologna.

Montresor, S. \& Vittucci Marzetti, G. (2007) Outsourcing and structural change. What can input-output analysis say about it?, Economia Politica, XXIV(1), pp. 43-78.

Naghavi, A. \& Ottaviano, G. (2005) Outsourcing, contracts and growth, mimeo, University of Bologna.

Pasinetti, L. L. (1973) The notion of vertical integration in economic analysis, Metroeconomica, 1, pp. 1-29.

Piachaud, B. S. (2002) Outsourcing in the pharmaceutical manufacturing process: an examination of the cro experience, Technovation, (2), pp. 81-90.

Pilat, D. \& Wölfl, A. (2005) Measuring the interaction between manufacturing and services, STI Working Paper 2005/5, OECD, Paris.

Postner, H. H. (1990) The contracting-out problem in service sector analysis: Choice of statistical unit, Review of Income and Wealth, 36(2), pp. 177-186.

Spencer, B. J. (2005) International outsourcing and incomplete contracts, Working Paper 11418, National Bureau of Economic Research. 
Stanback, T. M. (1979) Understanding the Service Economy (Baltimora: Johns Hopkins University Press).

United Nations (2006) System of national accounts 1993, Studies in Methods Series F, No.2, United Nations Statistics Division, New York.

Vittucci Marzetti, G. (2008) Input-output data and service outsourcing. a reply to Dietrich, McCarthy and Anagnostou, Working Papers 621, Department of Economics, University of Bologna.

Williams, K. et al. (1998) Cars: Analysis, History, Cases (USA: Berghahn Books).

Womack, J. P. \& Jones, D. (1994) From lean production to the lean enterprise, Harvard Business Review, March-April, pp. 93-103.

Womack, J. P. et al. (1990) The Machine That Changed the World: The Story of Lean Production (New York: Harper Collins Publishers).

Woodrow Eckard, E., Jr (1979) A note on the empirical measurement of vertical integration, Journal of Industrial Economics, 28(1), pp. 105-107.

Zaghini, E. (1967) Una nota sui subsistemi di Sraffa, Studi Economici, 22, pp. 290-305. 